University of Nebraska - Lincoln

DigitalCommons@University of Nebraska - Lincoln

$9-2008$

\title{
Convergent Validity of the Early Childhood Behavior Problem Screening Scale
}

\author{
Annette Griffith \\ University of Nebraska - Lincoln, agriffith2@unl.edu \\ J. Ron Nelson \\ University of Nebraska - Lincoln, rnelson8@unl.edu \\ Michael Epstein \\ University of Nebraska - Lincoln, mepstein1@unl.edu \\ Bjorn Pederson \\ University of Nebraska - Lincoln
}

Follow this and additional works at: https://digitalcommons.unl.edu/specedfacpub

Part of the Special Education and Teaching Commons

Griffith, Annette; Nelson, J. Ron; Epstein, Michael; and Pederson, Bjorn, "Convergent Validity of the Early Childhood Behavior Problem Screening Scale " (2008). Special Education and Communication Disorders Faculty Publications. 1.

https://digitalcommons.unl.edu/specedfacpub/1

This Article is brought to you for free and open access by the Department of Special Education and Communication Disorders at DigitalCommons@University of Nebraska - Lincoln. It has been accepted for inclusion in Special Education and Communication Disorders Faculty Publications by an authorized administrator of DigitalCommons@University of Nebraska - Lincoln. 


\title{
Convergent Validity of the Early Childhood Behavior Problem Screening Scale
}

\author{
Annette K. Griffith \\ J. Ron Nelson \\ Michael H. Epstein \\ Bjorn Pederson
}

University of Nebraska-Lincoln

\begin{abstract}
This study examined the convergent validity of the parent and teacher versions of the Early Childhood Behavior Problem Screening Scale (ECBPSS) with the Child Behavior Checklist (CBCL) and the Caregiver-Teacher Report Form (C-TRF), respectively. Data were collected on a sample of preschool and kindergarten students $(n=149)$ from two medium-sized cities in the Midwest. Analyses of both the parent and teacher versions of the ECBPSS were correlated with the corresponding Internalizing, Externalizing, and Total Problem scale scores of the CBCL and the C-TRF. The present findings and future research directions and limitations are discussed.
\end{abstract}

Keywords: behavioral assessment; behavior problems; screening; preschool and kindergarten children; convergent validity

$\mathrm{M}$ any individuals have argued for a need for early identification of and intervention for children who are at risk for emotional and behavioral disorders (EBD; Conroy \& Brown, 2004; Kauffman, 2005; Walker, Ramsey, \& Gresham, 2004). Whereas $10 \%$ to $30 \%$ of preschool-age children have displayed mild to moderate levels of problem behavior (e.g., Campbell, 1995; Fox, Jack, \& Broyles, 2005), those who are at risk for EBD have been identified rarely prior to beginning school (Conroy \& Brown, 2004). Many children have been identified with EBD when they are well into their school careers, with most referrals occurring in 9th and 10th grades (Walker et al., 2004) and usually only after their behavioral difficulties become unmanageable by classroom teachers (Gresham, 1991). By this time, problem behaviors have become more severe and resistant to intervention. In fact, researchers have reported that chronic and persistent problem behaviors in young children are linked to poor outcomes in adolescence and adulthood (e.g., Campbell, 1995, 2002; Patterson, Reid, \& Dishion, 1992). For example, Campbell (1995) found that as many as half of children who engaged in externalizing behaviors during their preschool years continued to do so during their school-age years, and Walker et al. (2004) noted that children with EBD past the age of 8 may have chronic social and vocational difficulties.

Current legislation has required school personnel to become proactive in their identification of children who display problem behavior (Fairbanks, Sugai, Guardino, \& 
Lathrop, 2007). Specifically, the Individuals With Disabilities Education Act has mandated that children who are in need of specific early intervention or special education services be identified through the statewide, comprehensive Child Find System (www. childfindidea.org). The increased emphasis on early identification and prevention encourages professionals to intervene with children before problem behaviors develop into EBD (Walker et al., 2004). As a result, many preschool (e.g., Fox \& Little, 2001) and school personnel (e.g., Sugai \& Horner, 2002) have incorporated the use of positive behavioral support programs to address children's behavioral difficulties.

One systematic approach that has begun to show promise is the three-tiered model of behavior prevention and intervention (cf. Sugai \& Horner, 2002). The three-tiered model has been intended not only to reduce problem behaviors in children with identified EBD but also, perhaps more important, to prevent the development of children's chronic and persistent behavioral difficulties. The model includes primary, secondary, and tertiary intervention levels (cf. Sugai \& Horner, 2002; Walker et al., 1996). The types and levels of intervention have been designed to provide specific services for children with different behavioral needs. At the primary level, preventative interventions have been used school- wide. These primary interventions have been used to enhance any protective factors that might reduce the likelihood that children will become at risk for EBD and should prevent problem behaviors before they become intractable. Primary interventions have appeared to be appropriate for the vast majority of children in a school. Secondary interventions have been employed with children who are at risk for EBD. They have been more intensive and designed to meet the more specific needs of children who have not responded to primary interventions. These secondary interventions have focused on behavioral, academic, or social supports in an attempt to reduce children's behavioral difficulties while enhancing their academic and social skills. Interventions at the tertiary level have been the most intensive and, ideally, will be more comprehensive than secondary interventions. Tertiary interventions have been designed for a relatively limited number of children who have not responded to either primary or secondary interventions and who may have been identified with EBD.

Intervention at the secondary level has been a key in the prevention of EBD, and universal screening procedures have been needed to screen children in a school who might be at risk for EBD and in need of more intensive and systematic intervention (cf. Walker et al., 1996). The use of early universal screening measures has appeared to be a proactive step to identify children and to provide them with early intervention (cf. Feil, Severson, \& Walker, 1998).

A behavioral measure for use at a universal level is dependent on several features. The measure needs to be psychometrically sound, developmentally appropriate for preschool- and kindergarten-age children, economical in terms of time and resources, and relatively easy to administer with large numbers of children (Feil, Severson, et al., 1998; Walker et al., 2004). Several behavioral rating scales, such as the Behavior Assessment System for Children (Reynolds \& Kamphaus, 2004), the Social Skills Rating System (Gresham \& Elliott, 1990), and the Preschool and Kindergarten Behavioral Scales (Merrell, 2002), have been developed and are useful for identifying children with behavior problems and for developing intervention plans. Whereas these measures have been demonstrated to be psychometrically sound and developmentally appropriate, they can be lengthy to complete, with 100, 40 to 49, and 72 items, respectively, and were not designed for use as universal screeners for children. 
To screen children for inclusion in secondary-level interventions, few psychometrically sound measures that are time efficient are available to use as universal screeners for children at risk for EBD. This is particularly the case at the preschool and kindergarten grades when children are first entering the educational system. Psychometrically sound screening measures that do exist (e.g., the Early Screening Project [ESP]; Walker, Severson, \& Feil, 1995) can be lengthy, time-consuming, or difficult for teachers to administer. For example, the ESP uses a three-stage process or set of protocols to identify children (i.e., teacher judgment, teacher rating on three screening measures, behavioral observations). In addition to an extensive set of protocols, the ESP requires extensive training to become proficient in the observation procedures. Together, these features limit its feasibility for use by school personnel at a universal level. Other screeners for young children (e.g., Temperament and Atypical Behavior Scale; Neisworth, Bagnato, Salvia, \& Hunt, 1999) focus on identifying children who are at risk for developing problem behavior but do not provide information on whether those behaviors are internalizing or externalizing, an important consideration for future assessment. With the expansion of many preschool programs around the nation, young children are entering school systems and other publicly funded programs at earlier ages than in the past. Therefore, an increased need for accurate screening instruments, which can be used to identify children who are at risk for EBD, exists.

To address the need for a brief, easy-to-implement screening measure that is developmentally appropriate for identifying preschool and kindergarten children who are specifically at risk for EBD, the Early Childhood Behavior Problem Screening Scale (ECBPSS; Epstein \& Nelson, 2006) was developed. The ECBPSS is a short, 12-item measure that can be completed in a relatively short time as a screening tool to identify young children who may require further assessment because they may be at risk for EBD. There are two forms of the ECBPSS, one that is completed by parents and one by teachers. Although cross-informant reliability findings across different types of raters (e.g., teacher-parent) have been only modest (e.g., McConaughy, Stanger, \& Achenbach, 1992; Nelson, Epstein, Griffith, \& Harper, 2007), the inclusion of parent information might provide additional behavioral information earlier in the school year, if not before it begins. Both the parent and teacher forms of the ECBPSS have been written below a sixth-grade reading level and comprise the same 12 items, with only slight wording changes between the forms. For each item, the rater is asked to consider the child's behavior and then rate the child on a scale that ranges from 0 (not at all like the child) to 3 (very much like the child). The higher a child's score on the measure, the greater his or her risk for developing problem behaviors.

The 12 items that compose the ECBPSS were obtained using a multistep process (Nelson, Stage, Duppong Hurley, Synhorst, \& Epstein, 2007). First, the professional literature was reviewed to identify 40 developmental factors that place children at risk for EBD across 11 domains. These domains included prenatal (e.g., maternal emotional distress), natal (e.g., premature birth, unusual delivery), postnatal (e.g., medical problems, prolonged hospital stay), antisocial and psychiatric family history (e.g., domestic violence, mental illness), family structure and socioeconomic status (SES; e.g., single parent, living in poverty), family functioning and parent management (e.g., high parent stress), maternal depression, externalizing behavior pattern during early childhood (e.g., impulsive, aggressive), internalizing behavior pattern during early childhood (e.g., fearful, socially withdrawn), childhood maladjustment (e.g., runaway, psychiat- 
ric hospitalization), and childhood maltreatment. To assess these 40 child development risk factors, a 123-item risk factor interview was developed for use with parents and primary caregivers of kindergarten-age children entering a secondary-level prevention program for children at risk of developing behavior problems. Using interview data collected for 156 children screened into the secondary behavior prevention program, two logistic regression analysis procedures were conducted to determine the most reliable and robust predictors of Child Behavior Checklist (CBCL; Achenbach \& Rescorla, 2000) Total Problem Behavior scores. The target variables for each of the logistic regression analyses were the dichotomized CBCL Total Problem Behavior broadband scores (i.e., behavior problems absent $=0$ or behavior problems present $=1$ ) that had been completed for the 156 children. The purpose of the initial logistic regression analysis was to identify the domains that were most predictive of problem behavior for inclusion in the final regression model. Each of the risk factor domains was included in a logistic regression analysis to predict total problem behavior. For each at-risk domain that was entered as a block into the analysis (e.g., in the postnatal domain, both medical problems and prolonged stay were entered together), an omnibus statistic needed to be statistically significant $(p<.05)$ for the domain to be considered for the second stepwise logistic regression analysis.

The purpose of the second stepwise logistic regression procedure was to identify the individual risk factors that provided the most reliable and robust prediction of total behavior problems. The analyses identified 12 risk factors that were highly predictive of CBCL Total Problem Behavior scores (see Table 1). The overall correct classification of true negative and true positive cases was $78 \%$ and $75 \%$, respectively. Thus, our preliminary research resulted in 12 items with largely moderate to high correlations (ranging from .18 to .94 ) and predictive of EBD.

The internal consistency and factor structure of the ECBPSS parent and teacher forms and the cross-informant reliability between parents and teachers were assessed in a previous study with preschool and kindergarten students (Nelson et al., 2007). Principal component factor analyses of the teacher and parent forms of the ECBPSS yielded internalizing and externalizing behavior factors comprising six items each. On the parent version, factor loadings ranged from .45 to .85 on the Internalizing scale and from .63 to .70 on the Externalizing scale, with eigenvalues of 5.67 and 2.25, respectively. On the teacher form, factor loadings ranged from .65 to .97 on the Internalizing scale and from .69 to .93 on the Externalizing scale, with eigenvalues of 7.22 and 6.57, respectively. These two factors are consistent with accepted theory in the field of childhood psychopathology (Achenbach \& Edelbrook, 1984; Achenbach \& Rescorla, 2000). For each of these factors, and the scale overall, the internal consistencies were quite high (greater than .83). Specifically, the overall internal consistencies of the teacher and parent forms were .87 and .95 for the preschool sample and .90 and .89 for the kindergarten sample, respectively. The internal consistencies of the internalizing and externalizing factors for both the teacher and parent forms were also quite high, ranging between .83 and .95. Pearson product moment correlations examining the interrater reliability of teachers and parents ranged from .32 to .37 across Internalizing, Externalizing, and Total Problem Behavior subscales.

Our present study builds directly off previous research by conducting a preliminary assessment of the convergent validity of the ECBPSS (cf. Salvia \& Ysseldyke, 2004). Specifically, we assessed the convergent validity of the teacher and parent forms of the 
Table 1. Items From the Early Childhood Behavior Problem Screening Scale (Epstein \& Nelson, 2006)

\begin{tabular}{ll}
\hline Item & Subscale \\
\hline Has difficulty adjusting to changes or new things & Internalizing \\
Upsets me just to be mean & Externalizing \\
Often cries or fusses over little things & Internalizing \\
Often does things that irritate or frustrate me & Externalizing \\
Destroys own toys or things & Externalizing \\
Often moody or irritable & Internalizing \\
Has a bad temper & Externalizing \\
Often does not do what is asked & Externalizing \\
Easily upset or frustrated & Internalizing \\
Physically abuses others & Externalizing \\
Is easily upset & Internalizing \\
Demands a lot of attention & Internalizing \\
\hline
\end{tabular}

ECBPSS with the CBCL and the Caregiver-Teacher Report Form (C-TRF; Achenbach \& Rescorla, 2000).

\section{Method}

\section{Participants}

Parents and teachers completed information on 149 children. Of the children whose behavior was rated, $49.7 \%$ were male and $50.3 \%$ were female. The participants were selected from preschool and kindergarten classrooms located in two midsized cities in Nebraska. Seven percent of the students had previously qualified for special education services, with 4 children identified with attention-deficit/hyperactivity disorder (ADHD; $2.7 \%), 1$ with EBD $(0.7 \%), 1$ as hearing impaired $(0.7 \%)$, 1 with posttraumatic stress (PTS; 0.7\%), 1 as speech language impaired (SLI; 0.7\%), and 1 with both SLI and EBD (0.7\%). The ethnicity was divided among European American (65.8\%), Hispanic (6.7\%), African American (2.7\%), Asian American (0.7\%), Native American (1.3\%), multiracial $(12.1 \%)$, and not given $(10.7 \%)$. English was spoken as the primary language of all participants.

Preschool children. A nonprofit organization working with low-income children served as the site for the preschool classrooms. Fifty-five of the students $(37 \%$ of the total sample) with a mean age of 4.01 years (range $=3$ to 5 years) attended the preschool. The ethnic composition of the sample was 60\% European American, 7.3\% African American, 3.6\% Hispanic, 1.8\% Asian American, 23.6\% multiracial, and 3.7\% not reported. Fifty-five percent were male and $45 \%$ were female. Eleven percent had been identified for special education services, with 1 student identified with ADHD (1.8\%), 2 with hearing impairment (3.6\%), 1 with EBD (1.8\%), 1 with PTS (1.8\%), and 1 with both SLI and EBD (1.8\%). 
Kindergarten children. The kindergarten classrooms were located in a public school system that provided free or reduced lunches for more than half of its students. Ninetyfour of the students (63\% of the sample) were in kindergarten, with a mean age of 5.72 years (range $=5$ to 6 years). The ethnicity of these students was $69.1 \%$ European American, 8.5\% Hispanic, 2.1\% Native American, 5.4\% multiracial, and 14.9\% not reported. Forty- seven percent were male and 53\% were female. Five percent were identified as receiving special education services, with 3 students identified with ADHD (3.2\%), 1 as hearing impaired $(1.1 \%)$, and 1 as SLI (1.1\%).

\section{Measures}

The convergent validity of the ECBPSS was assessed by correlating the Internalizing and Externalizing subscale scores and the total scale score of the parent ECBPSS form with the internalizing and externalizing broadband scores and the total score of the CBCL and by correlating the Internalizing and Externalizing subscale scores and the total scale score of the teacher ECBPSS form with the internalizing and externalizing broadband scores and the total score of the C-TRF. The CBCL is a 100-item parent-report measure used to assess problem behaviors in young children. The CBCL provides a total problem behavior score, two broadband scores for internalizing and externalizing behaviors, and seven specific syndrome scores (emotionally reactive, anxious-depressed, somatic complaints, withdrawn, sleep problems, attention problems, aggressive behavior). The C-TRF is also a 100-item measure and is completed by teachers or caregivers. Like the CBCL, the C-TRF is used to assess problem behaviors and yields a total problem behavior score, two broadband scores for internalizing and externalizing behaviors, and specific syndrome scores. The C-TRF excludes sleep problems, to include only six specific syndrome scores. For this study, the three total scores, internalizing, externalizing, and total problems, of both the CBCL and the C-TRF were used. The CBCL and the C-TRF were selected for convergent validity analyses because of their extensive use in both clinical and research settings and their previous demonstrations with sound psychometric properties (i.e., content, construct, and convergent validity and interrater, test-retest, and long-term reliability coefficients; see Achenbach \& Rescorla, 2000, for previous psychometric information). For example, test-retest reliability coefficients ranged from .68 to .92 for the CBCL and .57 to .91 for the C-TRF.

Parent forms. The ECBPSS Parent Form is a 12-item scale used to describe the behaviors of the child. Each item uses a 4-point Likert-type scale that ranges from 0 (not at all like my child) to 3 (very much like my child). Written at a sixth-grade reading level, the ECBPSS gives a total score and two subscale scores, for internalizing and externalizing behaviors. Higher scores on any of the scales indicate parental perceptions of the presence of more problem behaviors. The CBCL uses a 3-point Likert-type scale ranging from 0 (not true) to 2 (very true) and provides a total score and two subscale scores, for internalizing and externalizing behaviors. The higher the scores on the various scales, the more the behaviors are seen as a problem by the rater.

Teacher forms. The ECBPSS Teacher Form is identical to the parent form, a 12-item scale with a 4-point Likert-type rating of each item, written at a sixth-grade reading 
level. The calculation of the internalizing and externalizing score and the total score are the same as well. The C-TRF is similar to the CBCL and also uses a 3-point Likert-type scale and provides a total score and two subscale scores, for internalizing and externalizing behaviors. For both the ECBPSS Teacher Form and the C-TRF, the higher the score on the various scales, the more the behavior is seen as a problem by the rater.

\section{Procedures}

Thirty-one teachers in 14 preschool and 17 kindergarten classrooms were asked to participate in the study, and all teaching staff solicited agreed to participate and signed consent forms. Class lists were then obtained from teachers, and 341 parents were sent packets including an information letter and a consent form approved by the institutional review board. After 2 weeks, parents who had not returned a consent form were resent consent forms in a second packet that was identical to the first. Parental consent was obtained for 152 students, for a response rate of $47.3 \%$.

Teachers. Teachers were given a package that contained enough ECBPSS teacher forms and C-TRF scales to rate each of the children in their classroom whose parents had given written consent. Directions on how to complete each instrument were also included. Teachers who were late in returning the completed packages after 2 weeks received a reminder phone call. Teachers who did not respond within 1 month were sent a second package that contained the same materials as the first. Teachers returned 149 completed ECBPSS and C-TRF, for a response rate of $96 \%$.

Parents. Parents who provided written consent were mailed a package that included an ECBPSS form, a CBCL form, and directions on how to complete each instrument. Parents who did not return the completed forms within 2 weeks were given a reminder phone call. Parents not returning the completed forms within 1 month were again mailed the two forms and directions. Parents returned 134 completed ECBPSS and CBCL forms, for a response rate of $88 \%$.

\section{Results}

\section{Teacher ECBPSS and the C-TRF}

Because of the narrow developmental span between preschool and kindergarten children, overall analyses were run. As a group, the correlations between the ECBPSS Teacher Form and the C-TRF internalizing, externalizing, and total scores were moderate to high, ranging from .52 to .82 across all possible correlations. Specifically, the ECBPSS teacher Internalizing and Externalizing subscale scores' and total score's direct correlations to the C-TRF's counterpart of internalizing and externalizing broadband scores and total problem score were .66, .82, and .79, respectively. All correlations were significant at the $\mathrm{p}<.01$ level. Pearson product-moment correlation coefficients between the ECBPSS Teacher Form and the C-TRF are reported in Table 2, with results provided separately for preschool and kindergarten student. Means and standard deviations for both the ECBPSS Teacher Form and the C-TRF are also included in Table 2. 
Table 2. Correlation Coefficients Between the ECBPSS and the C-TRF for Preschool and Kindergarten Students

\begin{tabular}{|c|c|c|c|}
\hline \multirow[b]{2}{*}{ ECBPSS } & \multicolumn{3}{|c|}{ C-TRF } \\
\hline & $\begin{array}{l}\text { Internalizing } \\
\text { Broadband Score }\end{array}$ & $\begin{array}{l}\text { Externalizing } \\
\text { Broadband Score }\end{array}$ & $\begin{array}{c}\text { Total } \\
\text { Problem Score }^{\mathrm{c}}\end{array}$ \\
\hline \multicolumn{4}{|l|}{ Preschool $(n=55)$} \\
\hline Internal problem score ${ }^{\mathrm{d}}$ & $.71^{\star *}$ & $.52^{* *}$ & $.67^{* *}$ \\
\hline External problem score & $.72^{* *}$ & $.85^{\star *}$ & $.84^{* *}$ \\
\hline Total problem score ${ }^{\mathrm{f}}$ & $.78^{* *}$ & $.78^{* *}$ & $.84^{\star *}$ \\
\hline \multicolumn{4}{|l|}{ Kindergarten $(n=94)$} \\
\hline Internal problem scoreg & $.57^{\star *}$ & $.51^{* *}$ & $.62^{* *}$ \\
\hline External problem score ${ }^{h}$ & $.57^{* *}$ & $.82^{* *}$ & $.77^{* *}$ \\
\hline Total problem score $\mathrm{i}^{\mathrm{i}}$ & $.60^{* *}$ & $.75^{* *}$ & $.76^{* *}$ \\
\hline \multicolumn{4}{|c|}{ 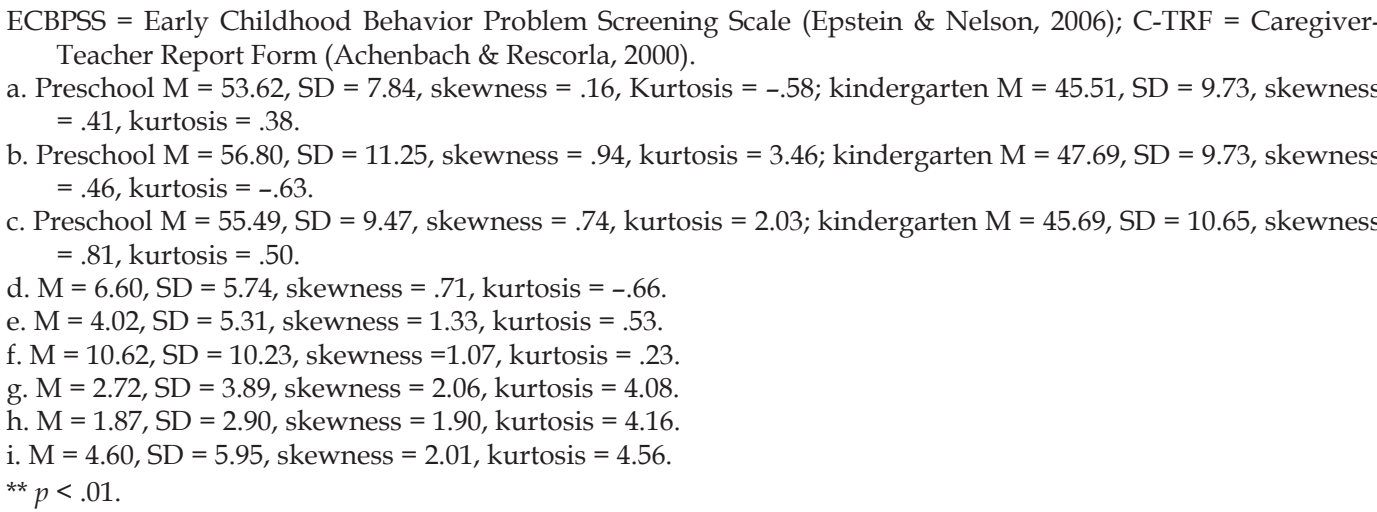 } \\
\hline
\end{tabular}

Preschool. For the preschool sample, the Pearson product-moment correlation coefficients were in the moderate to high ranges across all possible correlations of the preschool pairs, ranging from .52 to .85 , and the correlations were as expected. Specifically, the correlation between the Internalizing subscales of the ECBPSS Teacher Form and the C-TRF was .71, between the Externalizing subscales was .85, and between the Total Problem scales was .84. All correlations were significant at the $p<.01$ level.

Kindergarten. For the kindergarten sample, the Pearson product-moment correlation coefficients were moderate to high across all possible correlations, ranging from .51 to .82 . The correlation between the Internalizing subscales of the ECBPSS Teacher Form and CTRF was .57, between the Externalizing subscales was .82, and between the Total Problem scales was .76, respectively. All correlations were significant at the $p<.01$ level.

\section{Parent ECBPSS and the CBCL}

For the total number of ECBPSS Parent Form and CBCL pairs $(n=134)$, the correlations were moderate to high, ranging from .53 to .84 across all possible correlations. 
Table 3. Correlation Coefficients Between the ECBPSS and the CBCL for Preschool and Kindergarten Students

\begin{tabular}{|c|c|c|c|}
\hline \multirow[b]{2}{*}{ ECBPSS } & \multicolumn{3}{|c|}{ C-TRF } \\
\hline & $\begin{array}{l}\text { Internalizing } \\
\text { Broadband Score }\end{array}$ & $\begin{array}{c}\text { Externalizing } \\
\text { Broadband Score }\end{array}$ & $\begin{array}{c}\text { Total } \\
\text { Problem Score }^{\mathrm{c}}\end{array}$ \\
\hline \multicolumn{4}{|l|}{ Preschool $(n=54)$} \\
\hline Internal problem score ${ }^{\mathrm{d}}$ & $.72^{* *}$ & $.51^{* *}$ & $.69^{* *}$ \\
\hline External problem score & $.80^{* *}$ & $.79 * *$ & $.89^{* *}$ \\
\hline Total problem score ${ }^{f}$ & $.81^{* *}$ & $.72^{* *}$ & $.86^{* *}$ \\
\hline \multicolumn{4}{|l|}{ Kindergarten $(\mathrm{n}=80)$} \\
\hline Internal problem scoreg & $.61^{* *}$ & $.55^{\star *}$ & $.62^{* *}$ \\
\hline External problem score ${ }^{h}$ & $.71^{\star *}$ & $.79^{* *}$ & $.80^{* *}$ \\
\hline Total problem score ${ }^{\mathrm{i}}$ & $.70^{* *}$ & $.70^{* *}$ & $.75^{* *}$ \\
\hline $\begin{array}{l}\text { ECBPSS = Early Childhood Be } \\
\text { Checklist (Achenbach \& } \mathrm{R} \\
\text { a. Preschool } \mathrm{M}=48.19, \mathrm{SD}=1 \\
\quad=.39, \text { kurtosis }=-.66 . \\
\text { b. Preschool } \mathrm{M}=48.19, \mathrm{SD}=1 \\
\quad 57, \text { kurtosis }=-.61 . \\
\text { c. Preschool } \mathrm{M}=48.19, \mathrm{SD}=1 \\
\quad=.47, \text { kurtosis }=-.17 \\
\text { d. } \mathrm{M}=7.41, \mathrm{SD}=3.90, \text { skewn } \\
\text { e. } \mathrm{M}=4.87, \mathrm{SD}=3.55, \text { skewne } \\
\text { f. } \mathrm{M}=13.48, \mathrm{SD}=7.34 \text {, skewn } \\
\text { g. } \mathrm{M}=6.58, \mathrm{SD}=4.00, \text { skewn } \\
\text { h. } \mathrm{M}=3.98, \mathrm{SD}=3.25, \text { skewn } \\
\text { i. } \mathrm{M}=11.66, \mathrm{SD}=7.47, \text { skewn } \\
\text { ** } p<.01 .\end{array}$ & $\begin{array}{l}\text { vior Problem Screenin } \\
\text { corla, 2000). } \\
\text { 37, skewness = }-.07, \mathrm{ku} \\
\text { 37, skewness }=.53, \mathrm{kur} \\
\text { 37, skewness }=.33, \mathrm{kur} \\
=.45, \text { kurtosis }=.13 . \\
=1.37, \text { kurtosis }=3.04 . \\
=.74, \text { kurtosis }=1.43 . \\
=.33, \text { kurtosis }=-.77 . \\
=1.00, \text { kurtosis }=.13 . \\
=.67, \text { kurtosis }=1.43 .\end{array}$ & $\begin{array}{l}\text { ale }(\text { Epstein \& Nelson, } \\
\text { is }=-.62 ; \text { kindergarten } \\
=.02 ; \text { kindergarten } \mathrm{M} \\
\mathrm{S}=-.66 ; \text { kindergarten }\end{array}$ & $\begin{array}{l}\mathrm{CBCL}=\text { Child Behavior } \\
38, \mathrm{SD}=9.84, \text { skewness } \\
8, \mathrm{SD}=9.84, \text { skewness }= \\
.38, \mathrm{SD}=9.84, \text { skewness }\end{array}$ \\
\hline
\end{tabular}

Specifically, the ECBPSS Parent Form Internalizing and Externalizing subscale scores' and total score's direct correlations to the CBCL's counterpart of internalizing and externalizing broadband score and total problem score were .66, .79, and .80, respectively. All correlations were significant at the $p<.01$ level. Pearson product-moment correlation coefficients between the ECBPSS Parent Form and the CBCL are reported in Table 3 and separated between preschool and kindergarten students. Means and standard deviations for both the ECBPSS Parent Form and the CBCL are also included in Table 3.

Preschool. For the 54 returned pairs of the ECBPSS Parent Form and CBCL form, the Pearson product-moment correlation coefficients were in the moderate to high ranges across all possible correlations of the preschool pairs, ranging from .51 to .89. The correlation between the Internalizing subscales of the ECBPSS Parent Form and CBCL was .72, between the Externalizing subscales was .79, and between the Total Problem scales was .86. All correlations were significant at the $p<.01$ level.

Kindergarten. For the 80 returned pairs of the ECBPSS Parent Form and CBCL form, the Pearson product-moment correlation coefficients were in the moderate to high 
ranges across all possible correlations, ranging from .55 to .80 . The correlation between the Internalizing subscales of the ECBPSS and CBCL was .61, between the Externalizing sub- scales was .79, and between the Total Problem scores was .75. All correlations were significant at the $p<.01$ level.

\section{Discussion}

Our study assessed the convergent validity of both the parent and teacher versions of the ECBPSS using data collected from a sample of preschool- and kindergarten-age children. Both the parent and teacher versions of the ECBPSS showed statistically significant correlations with the Internalizing, Externalizing, and Total Problem scale scores of the CBCL and the C-TRF, ranging from .51 to .89 and from .51 to .85 , respectively. For each version of the ECBPSS, all correlations were greater than .51, with more than half of all correlations greater than .70. The majority of the correlations were as expected, with students who obtained high scores on a particular scale of the ECBPSS also obtaining a high score on that scale of the CBCL and C-TRF. This indicates that similar to the CBCL and C-TRF, the ECBPSS is measuring the internalizing, externalizing, and total behavior problem constructs that it is intending to measure.

It should be noted, however, that some of the correlations were greater between dissimilar constructs than between similar constructs. For example, the correlation between the externalizing factor of the parent version of ECBPSS and the externalizing factor of the CBCL was lower than the correlation between the externalizing factor of the ECBPSS and the internalizing factor of the CBCL for the preschool sample. This is not surprising, as young children often do not exhibit solely internalizing or solely externalizing behavior. Often these two types of behavior occur together, with children who exhibit high levels of one type of behavior also exhibiting high levels of the other type of behavior (Achenbach \& Rescorla, 2000; McConaughy \& Skiba, 1993). In fact, Achenbach and Rescorla (2000) reported that for preschool and kindergarten samples, the mean correlation between scores on Internalizing and Externalizing scales was .50, indicating that measurements of these two constructs were not mutually exclusive. Although there are only six items in each subscale and some of the correlations were not as expected, the majority of them were. Several scales used to assess child behavior also contain subscales with a small number of items and have been demonstrated to have valid and reliable measurement properties in previous studies (e.g., Scale for Assessing Emotional Disturbance; Epstein \& Cullinan, 1998; Behavior and Emotional Rating Scale-2; Epstein \& Sharma, 1998). With the findings of Achenbach and Rescorla in mind, retaining the option for teachers and school personnel to employ an internalizing score, an externalizing score, or both is important, as outcomes for children who display different types of behavior problems may need different types of assessments.

Early identification and intervention for young children at risk for EBD have been discussed as key factors in the prevention of and intervention with EBD. Providing universal screening for all children as they enter the school system will allow identification to occur as early as possible. Whereas the CBCL and C-TRF are both widely used and researched measures for identifying children with EBD, neither are intended for use as universal screeners and are thus not particularly efficient for use with large numbers of children. However, the correlations between the parent and teacher versions of the ECBPSS and the CBCL and C-TRF, respectively, indicate that the ECBPSS may be a use- 
ful screener for identifying young children who may be at risk for developing EBD and may be employed as a universal screener to identify children as they enter preschool and kindergarten programs. The present study provided only initial data regarding the ECBPSS. However, our findings combined with results from previous research (e.g., Nelson et al., 2007) have shown that the ECBPSS may be used as a psychometrically sound measure. Nevertheless, additional replications and research are warranted.

\section{Study Limitations}

As the present research was an initial study, several limitations should be noted. First, the participants in this study were obtained from a convenience sample and were not randomly selected. Parents of preschool- and kindergarten-age children in only two settings were contacted to participate. Therefore, the children who participated were likely not representative of all the children for whom this measure could be potentially useful. In addition, although the percentage of parents who provided consent was relatively high, there may have been response bias and fundamental differences between those who did and did not provide consent for their children to participate. This further limited the ability of the screening instrument to represent the population of interest. Future research could be improved by randomly selecting students from a larger, more diverse sampling frame of students or by using stratified sampling procedures to ensure that the sample is representative of some larger population.

Second, data were collected from children, parents, and teachers in only two cities in Nebraska, and thus it is unlikely that the findings from this study are generalizable to children in other geographic locations. Again, generalizability of the results might be improved by broadening the geographic locations of the students participating in the research and by using stratified sampling procedures to ensure that the samples are geographically representative.

Third, the samples in the studies were modest and as such are not representative of children with disabilities or children of varied ethnic and cultural backgrounds. Future research that collects information on a more diverse group of students might increase the likelihood of a heterogeneous sample that may produce results that are representative of students with different disabilities and across varied ethnic and cultural backgrounds and geographic locations.

Fourth, unfortunately, the SES of the specific children in the study is not known. Although other demographic information, such as age, gender, and ethnicity, is reported, knowledge of SES might also be beneficial, given that SES is a factor that has been related to the occurrence of EBD. Thus, future research may benefit from the collection of more comprehensive demographic characteristics, including SES. Without detailed knowledge of the demographic characteristics of the children, it is difficult to generalize findings to specific populations or to generate hypotheses about for whom the measure may be useful.

Fifth, unfortunately, demographic information is not available for the parents and teachers who completed the behavioral rating scales. Although the behavior of the children was the focus of the study, knowledge about the parents and teachers who provided the data is sorely needed. This is particularly true because previous research has indicated that the presence of particular parent and teacher characteristics (e.g., SES) may influence perceptions of child behavior (Cullinan \& Kauffman, 2005). In addition, 
as discussed above, ensuring that parents and teachers are representative of national norms in regard to factors such as demographics and geographic location would improve the likelihood that those samples will be generalizable to other populations.

Finally, as this was an initial investigation, the convergent validity for each version of the ECBPSS was assessed with only one other measure (either the CBCL for the parent version or the C-TRF for the teacher version). Because the findings from the present study indicate promise for the use of the ECBPSS as a universal screener, future studies might focus on examining the convergent validity of the ECBPSS with other measures that are used to assess levels of problem behavior, such as the Scale to Assess Emotional Disturbance (Epstein \& Cullinan, 1998) or the Behavior Assessment System for Children-Second Edition (BASC-2; Reynolds \& Kamphaus, 2005). Although the CBCL and the C-TRF have been well researched and demonstrated to be psychometrically sound measures, knowledge of the convergence between the ECBPSS and other measures of behavior should add to the evidence of the psychometric nature of the ECBPSS.

Investigators also need to further examine other psychometric properties of the ECBPSS. For example, studies are needed to examine the interrater reliability (e.g., teacherteacher, parent-parent), cross-informant agreement (e.g., teacher-parent), test-retest reliability, predictive validity (e.g., ECBPSS scores to later EBD classification), divergent validity (e.g., ECBPSS to measures that identify child strengths), and discriminant validity (e.g., children with disabilities vs. children with behavior problems) of the ECBPSS. These replication studies are necessary to enhance confidence that the ECBPSS is a useful measure for screening children at risk for EBD.

\section{Conclusion}

Although additional research and replications are needed to further establish the psychometric nature of the ECBPSS, research to date has shown that the scale appears to measure the intended constructs of internalizing and externalizing behavior that are consistent with accepted behavioral constructs in the field of EBD. Therefore, the ECBPSS shows much promise as a screening tool for the identification of preschool- and kindergarten-age children who are in need of further behavioral assessment or early intervention. Moreover, appropriate screening and follow-up assessment may promote effective and efficient early identification and prevention and intervention efforts by practitioners (cf. Conroy \& Brown, 2004).

\section{References}

Achenbach, T. M., \& Edelbrook, C. S. (1984). Psychopathology of childhood. Annual Review of Psychology, 35, 227-256.

Achenbach, T. M., \& Rescorla, L. A. (2000). Manual for the ASEBA preschool forms and profiles. Burlington: University of Vermont; Research Center for Children, Youth, and Families.

Campbell, S. (1995). Behavior problems in preschool children: A review of recent research. Journal of Child Psychology and Psychiatry, 36, 113-149.

Campbell, S. B. (2002). Behavior problems in preschool children: Clinical and developmental issues (2nd edi tion). New York: Guilford.

Conroy, M. A., \& Brown, W. H. (2004). Early identification, prevention, and early intervention with young children at risk for emotional or behavioral disorders: Issues, trends, and a call for action. Behavioral Disorders, 29, 224-236. 
Cullinan, D., \& Kauffman, J. M. (2005). Do race of student and race of teacher influence ratings of emotional and behavioral problem characteristics of students with emotional disturbance? Behavior Disorders, 30, 393-402.

Epstein, M. H., \& Cullinan, D. (1998). Scale for Assessing Emotional Disturbance. Austin, TX: Pro-Ed.

Epstein, M. H., \& Nelson, J. R. (2006). Early Childhood Behavior Problem Screening Scale. Lincoln: University of Nebraska, Center for At-Risk Children's Services.

Epstein, M. H., \& Sharma, J. (1998). Behavioral and Emotional Rating Scale: A strengths-based approach to assessment. Austin, TX: Pro-Ed.

Fairbanks, S., Sugai, G., Guardino, D., \& Lathrop, M. (2007). Response to intervention: Examining classroom behavior support in second grade. Exceptional Children, 73, 288-310.

Feil, E. G., Severson, H. H., \& Walker, H. M. (1998). Screening for emotional and behavioral delays: The Early Screening Project. Journal of Early Intervention, 21, 252-266.

Feil, E. G., Walker, H. M., \& Severson, H. H. (1998). The Early Screening Project for young children with behavior problems. Journal of Emotional and Behavioral Disorders, 3, 194-202.

Fox, L., Jack, S., \& Broyles, L. (2005). Program-wide positive behavioral support: Supporting young children's social-emotional development and addressing challenging behavior. Tampa: University of South Florida, Louis de la Parte Florida Mental Health Institute.

Fox, L., \& Little, N. (2001). Starting early: Developing school-wide behavior support in a community preschool. Journal of Positive Behavior Interventions, 3, 251-254.

Gresham, F. M. (1991). Conceptualizing behavior disorders in terms of resistance to intervention. School Psychology Review, 20, 23-36.

Gresham, F. M., \& Elliott, S. N. (1990). Social Skills Rating System. Circle Pines, MN: American Guidance Service.

Kauffman, J. M. (2005). Characteristics of emotional and behavioral disorders of children and youth. Upper Saddle River, NJ: Pearson Merrill Prentice Hall.

McConaughy, S. H., \& Skiba, R. J. (1993). Comorbidity of externalizing and internalizing problems. School Psychology Review, 22, 421-437.

McConaughy, S. H., Stanger, C., \& Achenbach, T., M. (1992). Three-year course of behavioral/emotional problems in a national sample of 4- to 16-year-olds: 1. Agreement among informants. Journal of the American Academy of Child and Adolescent Psychiatry, 31, 932-940.

Merrell, K. W. (2002). Preschool and Kindergarten Behavior Scales-Second Edition. Austin, TX: Pro-Ed.

Neisworth, J. T., Bagnato, S. J., Salvia, J., \& Hunt, F. M. (1999). Temperament and Atypical Behavior Scale. Baltimore: Brookes.

Nelson, J. R., Epstein, M. H., Griffith, A. K., \& Harper, J. (2007). Factor structure, internal consistency, and inter-rater reliability of the Early Childhood Behavior Problem Screening Scale. Topics in Early Childhood Special Education, 27, 148-154.

Nelson, J. R., Stage, S. A., Duppong Hurley, K., Synhorst, L., \& Epstein, M. H. (2007). Risk factors predictive of the problem behavior of children at risk for emotional and behavioral disorders. Exceptional Children, 73, 367-379.

Patterson, G. R., Reid, J. B., \& Dishion, T. J. (1992). Antisocial boys. Eugene, OR: Castalia.

Reynolds, C. R., \& Kamphaus, R. W. (2004). Behavior Assessment System for Children (2nd ed.). Bloomington, $\mathrm{MN}$ : Pearson.

Salvia, J.,\& Ysseldyke,J. E. (2004). Assessment in special and inclusive education (9th ed.). Boston: Houghton Mifflin.

Sugai, G., \& Horner, R. (2002). The evolution of discipline practice: School-wide positive behavior supports. Child and Family Behavior Therapy, 24, 23-50.

Walker, H. M., Horner, R. H., Sugai, G., Bullis, M., Sprague, J. R., Bricker, D., et al. (1996). Integrated approaches to preventing antisocial behavior patterns among school-age children and youth. Journal of Emotional and Behavioral Disorders, 4, 194-209.

Walker, H. M., Ramsey, E., \& Gresham, F. M. (2004). Antisocial behavior in school: Evidence-based practices (2nd ed.). Belmont, CA: Wadsworth/Thomson Learning.

Walker, H. M., Severson, H. H., \& Feil, E. G. (1995). Early Screening Project. Longmont, CO: Sopris West. 